\title{
Rheological study of the gel phenomena during epoxide network formation in presence of sepiolite
}

Andrés Nohales ${ }^{2}$, Daniel López ${ }^{3}$, Mario Culebras ${ }^{1}$, Clara M Gómez $^{1 \star}$
${ }^{1}$ Institut de Ciencia dels Materials (ICMUV) Universitat de València. Catedrático Beltrán, 2. 46980 Paterna, Valencia. SPAIN
${ }_{4}^{2} \mathrm{R} \&$ D Department, UBE Corporation Europe SA, PO Box 118, $12080, \begin{aligned} & \text { Con formato: Español (España- } \\ & \text { alfab. internacional) }\end{aligned}$
Castellon (Spain)

${ }^{3}$ Instituto de Ciencia y Tecnología de Polímeros, CSIC. Calle Juan de la Cierva,

3. 28006 Madrid. SPAIN 


\section{ABSTRACT}

The dynamic behavior during the cross-linking of an epoxy polymer near the gel point has been monitored by rheological multiple frequency experiments. The influence of needle-like shape inorganic nanofiller, sepiolite, either non-modified or organically surface modified during the cure process in presence of an aliphatic and an aromatic hardener has been investigated. The validity of different criteria to determine the gel point was examined for the cross-linking of these filled thermosets. Winter-Chambon criterion at the gel point is obeyed by the unfilled and by the non-modified sepiolite filled epoxy matrix with either of the two hardeners. However, physical gels have been formed in presence of the organically modified sepiolite and the Winter-Chambon criterion is not valid. For all the systems investigated, the nanofiller reduces the time to reach gelation. Critical relaxation exponents and gel strength have been determined indicating more elastic and stronger gel in presence of the aliphatic hardener.

KEYWORDS: epoxy resin, sepiolite, gelation, rheology 


\section{INTRODUCTION}

Epoxy resins are among the best polymeric materials being used in many fields, especially in the aviation industry as adhesives and in structural applications as the matrix materials of fiber-reinforced composites. The more outstanding properties of these matrices are superior strength, stiffness, good chemical and heat resistance, excellent adhesion and low shrinkage properties. However, they exhibit low impact strength, poor resistance to crack propagation and small elongation at break, i.e., they are relatively brittle materials. ${ }^{1,2}$

In order to modify epoxy properties, polymer-clay nanocomposites constitute a new class of materials where nanoscale clay particles are molecularly dispersed within a polymer matrix ${ }^{2,3}$. The interest on these materials stems from the fact that nanoparticle addition can dramatically change some properties of the polymer matrix such as tensile strength, heat resistance, gas permeability etc. with very low loadings of the inorganic filler (1-10 wt\%). Much work has been devoted in obtaining improved matrices with very well dispersed nanoparticles. However, the factors that control the formation of such hybrids are not wellunderstood.

Most of polymer matrix modification with inorganic nanofillers employs a family of laminar clays, smectite clays, i.e. montmorillonite, MMT. This is a well-known natural and low-priced layered silicate that shows high aspect ratio, high surface area, and swelling ability. Because of its high cation exchange capacity easily turns it organophilic. In order to widen the research of the influence of inorganic nanofillers on the properties of epoxy matrices, in this work, we investigate the potential use of sepiolite, a nanofiller of needle-like shape, as potential 
nanofiller for epoxy resins. Sepiolite is a family of fibrous hydrated magnesium silicate with the theoretical half unit-cell formula $\mathrm{Si}_{12} \mathrm{O}_{30} \mathrm{Mg}_{8}(\mathrm{OH}, \mathrm{F})_{4}\left(\mathrm{OH}_{2}\right)_{4} \cdot 8 \mathrm{H}_{2} \mathrm{O}$. ${ }^{4,5}$ It has a structure similar to the 2:1 layered structure of MMT, formed by two tetrahedral silica sheets enclosing a central sheet of octahedral magnesia, except that the layers lack continuous octahedral sheets (Scheme 1). ${ }^{6,7}$ The discontinuous nature of the octahedral sheet allows for the formation of rectangular channels aligned in the direction of the axis of the particle, which contain some exchangeable $\mathrm{Ca}^{2+}$ and $\mathrm{Mg}^{2+}$ cations, and "zeolitic water". These nanostructured tunnels account in large part for the high specific surface area, and excellent sorption properties of sepiolite. In addition, it has good mechanical strength and thermal stability. These properties make sepiolite ideal for reinforcement of polymer materials, and it has been recently used for the reinforcement of elastomers ${ }^{8-11}$, thermoplastic polymers ${ }^{12-15}$, thermosets ${ }^{16-19}$ and biopolymers ${ }^{4}$.

The cure of a thermoset polymer, such as an epoxy, is a complex process that involves many chemical reactions. Gelation and vitrification are the significant phenomena that determine the characteristics of the polymer network. The cure process begins by formation and expansion of linear chains that soon start to branch, and subsequently to cross-link, originating three dimensional networks. ${ }^{1,2}$ The irreversible transformation from a viscous liquid to an elastic gel is named "gel point", that can be defined ${ }^{1,2,20}$ as the instant at which the weight average molecular weight tends to infinity. 
a)

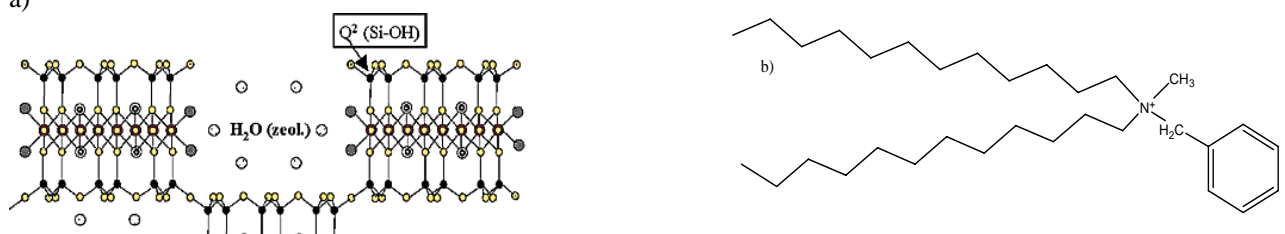

Scheme 1. (a) Crystalline and fibre

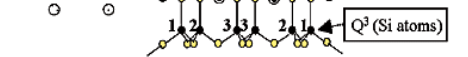

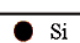
0 () $\mathrm{Mg}$ () $\mathrm{MgOH}$ (-) $\mathrm{SiOH}$ $\mathrm{H}_{2} \mathrm{O}$ (coord.) structure of sepiolite; (b) Surface organo-modifier of sepiolite B5.

Several theories have been employed to determine the gel point including the determination of divergence point of the steady state shear viscosity $(\eta)$ or normal stress (N1), the cross-over point of G' (dynamic elastic modulus) and G" (dynamic viscous modulus) ${ }^{21}$. However, Winter-Chambon criterion is commonly used in polymer gels. In accordance with Winter-Chambon criterion, the loss tangent $(\tan \delta)$ is independent of the frequencies at the gel point for most of the polymers. The frequency-independence of the loss tangent in the vicinity of the gel point has been widely used to examine chemical and physical gels and has also been employed to determine the gel point. ${ }^{21-24}$ The question is whether or not the Winter-Chambon criterion would be applicable for the cross-linking of epoxy thermosetting polymers in the presence of sepiolite.

The aim of this study concerns the measurement of the dynamic viscoelastic properties of epoxy-amine networks buildup as a function of curing time and oscillatory frequency. Different methods employed to determine the gel point of 
an epoxy resin have been tested when these systems are modified by an inorganic nanofiller, sepiolite. Two different amine curing agents, one aliphatic and the other aromatic, have been used to cure the epoxy resin.

Consequently, monitoring the rheological behavior of sepiolite-filled epoxy resins during the cure reaction may lead to better control of solid state properties. Therefore, in this work, we varied two parameters: 1) the type of sepiolite used, non-modified and surface-functionalized, and 2) the curing agent, aliphatic or aromatic, since the choice of curing agent and conditions would determine the final material properties. 


\section{EXPERIMENTAL}

\section{Materials}

The epoxy resin used was Araldite ${ }^{\circledR}$ GY250, a commercial diglycidyl ether of bisphenol-A kindly provided by Vantico Spain. The epoxy content was 5.34 eq $/ \mathrm{kg}$, as determined by acid titration, with a weight per equivalent of $187.3 \mathrm{~g} / \mathrm{eq}$ and a hydroxyl/epoxy oligomer molecules ratio of 0.122 . The curing agents were a diamine terminated polypropylene oxide Jeffamine D230 (D230) kindly supplied by Huntsman Corporation (equivalent $[\mathrm{H}]$ weight: 57.5 ) and an aromatic diamine 4,4'-methylene-bis-(2,6 diethyl) aniline (MDEA) supplied by Lonza Cure. Sepiolite Pangel ${ }^{\circledR}$ kindly supplied by Tolsa (Spain) was used as nanofiller. The dimensions of a single sepiolite fibre vary between 0.2 and $3 \mu \mathrm{m}$ in length, 10-30 nm in width and 5-10 nm in thickness, with an average aspect ratio of about 27 . Sepiolite has a surface area of about $300 \mathrm{~m}^{2} \mathrm{~g}^{-1}$, and a surface energy of about $240 \mathrm{mJm}^{-2} .{ }^{25}$ The clay modifiers were the unmodified sepiolite Pangel S9 and the organically modified sepiolite Pangel B5 (a surface modified sepiolite with benzyl dimethyl alkyl ammonium in order to make it more compatible with low polarity polymers). (see Scheme 1)

\section{Sample preparation}

Sepiolite dispersions in the epoxy pre-polymer were obtained as follows: the clay dried jn an oven at $120{ }^{\circ} \mathrm{C}$ was slowly added to the required amount of epoxy pre-polymer and then dispersed by a high-speed mixer Dispermat ${ }^{\circledR}$ CN20 (VMA-Getzmann GMBH, Germany) at $7200 \mathrm{rpm}$ with a $5 \mathrm{~cm}$ diameter disk for 25 min. The mixture was completely degassed under vacuum at $75^{\circ} \mathrm{C}$. The 
sepiolite loading expressed as grams of sepiolite per hundred grams of resin (phr) were as follows: 0, 2.5, 5.0 and $7.5 \mathrm{phr}$. The curing agent (Jeffamine D230 or MDEA) was added to the sepiolite/pre-polymer dispersions at a stoichiometric ratio epoxy/amine, $[E] /[H]=1$, then the mixture was stirred for 8 min, degassed and poured out between the rheometer plates to carry out the rheological experiments.

\section{Rheological Measurements}

Rheological oscillatory measurements were performed on a controlled stress rheometer TA Instruments AR1000N, using the parallel plate (25 mm diameter) shear mode to measure the storage modulus, G', the loss modulus, G" and the loss tangent, $\tan \delta$. The thickness of the samples was about $1.0 \mathrm{~mm}$. In order to reinitialize the dispersions, a steady pre-shear was performed ${ }_{2}$ at a shear rate of $500 \mathrm{~s}^{-1}$ for $5 \mathrm{~min}$, at room temperature, followed by a 120 min resting time before each dynamic experiment.

The rheological study of the curing process was performed at $75^{\circ} \mathrm{C}$ for the Jeffamine D230 system and at $130{ }^{\circ} \mathrm{C}$ for the MDEA system. Time sweeps were carried out in a multi-frequency experiment (frequencies between 5 and 50 $\mathrm{rad} / \mathrm{s})$. The applied oscillatory torque was varied between 10 and $100 \mu \mathrm{Nm}$ at increasing curing times to assure that the experiments were performed within the linear viscoelastic region. 


\section{RESULTS AND DISCUSSION}

Multifrequency rheological experiments were performed during the buildup of an epoxy network cured with either an aliphatic or an aromatic diamine in absence and presence of sepiolite to determine rheological behavior near the gel point. Several models have been proposed in the literature to study gelation. Among them, three have been selected in this paper. These are:

1) based on scaling laws, the gel point is the point of crossover of the elastic, G', and the loss, G", moduli in small-amplitude oscillatory experiments ${ }^{26}$;

2) Winter showed ${ }^{20,23,27,28}$ that the first definition was not universal but only valid for step-growth polymerizations of balanced stoichiometry. Accordingly, a more general method of detecting the gel point from dynamic moduli data is based on the observation ${ }^{23}$ that, at the gel point, $\tan \delta$ is independent of frequency and is given by:

$$
\tan \delta(\omega)=\frac{\mathrm{G}^{\prime}(\omega)}{\mathrm{G}^{\prime \prime}(\omega)}=\tan \left(\frac{\mathrm{n} \pi}{2}\right)
$$

where $\mathrm{n}$ is the relaxation exponent and can be linked to structural parameters of the network as we shall explain later. The value of tan $\delta$ independent of frequency enables us to determine the value of $n$. In the special case where $n=1 / 2$, it follows from eq 1 that $\tan \delta=1, G^{\prime}$ crosses over $G^{\prime \prime}$ and the gel point can be determined from G' and G" plots as in model 1.

3) In addition, and based on percolation models ${ }^{29}$ in the region close to the gel point the elastic and loss moduli can be represented by the power laws: 
$\mathrm{G}^{\prime}(\omega)=\mathrm{A}_{\mathrm{G}^{\prime}} \omega^{\mathrm{n}^{\prime}}$

$G^{\prime \prime}(\omega)=A_{G^{\prime \prime}} \omega^{n "}$

being $A_{G^{\prime}}$ and $A_{G^{\prime \prime}}$ the pre-exponential factors, $\omega$ the angular frequency and $n^{\prime}$ and $n "$ the power law exponents. The gel point is attained when $n^{\prime}=n^{\prime \prime}=n$.

The relaxation exponent can be related to structural parameters of the network such as the fractal dimension, $d_{f}$ and the gel strength, $S_{g}$. Thus, Muthukumar proposed the following expression to relate the exponent $n$ with excludedvolume and hydrodynamic screening effects ${ }^{30}$ :

$\mathrm{n}=\frac{\mathrm{d}\left(\mathrm{d}+2-2 \mathrm{~d}_{\mathrm{f}}\right)}{2\left(\mathrm{~d}+2-\mathrm{d}_{\mathrm{f}}\right)}$

where $d=3$ is the Euclidean space dimension. All values of the relaxation exponent for $0<n<1$ are possible for a fractal dimension in the physically acceptable range $1 \leq d_{f} \leq 3$.

Winter and coworkers ${ }^{20,23,28}$ can describe the rheological behavior at the point of gelation in terms of the gel strength of the material at the condition of critical gelation:

$G^{t r}(w)=G^{n}(w) / \tan (n \pi / 2)=\Gamma(1-n) \cos (n \pi / 2) S_{\downarrow} g w^{t} n$

The shear relaxation $G(t)$ modulus is expected to obey a power law relaxation at the gel point:

$G(t)=S_{g} t^{-n}$ 
where $t$ is the relaxation time and the equation assumes that there is no chemical reaction occurring. The parameter $\mathrm{n}$ is the critical relaxation exponent and determines the stress relaxation rate at the gel point. $S_{g}$ is the gel strength and can be simply considered as the relaxation modulus at the gel point when the relaxation time is one second. $S_{g}$ represents the elastic modulus or the rigidity of the system when $n=0$, while it represents the viscosity when $n=1 . S_{g}$ can be calculated from equation 5 at the gel point, if $\mathrm{n}$ is known.
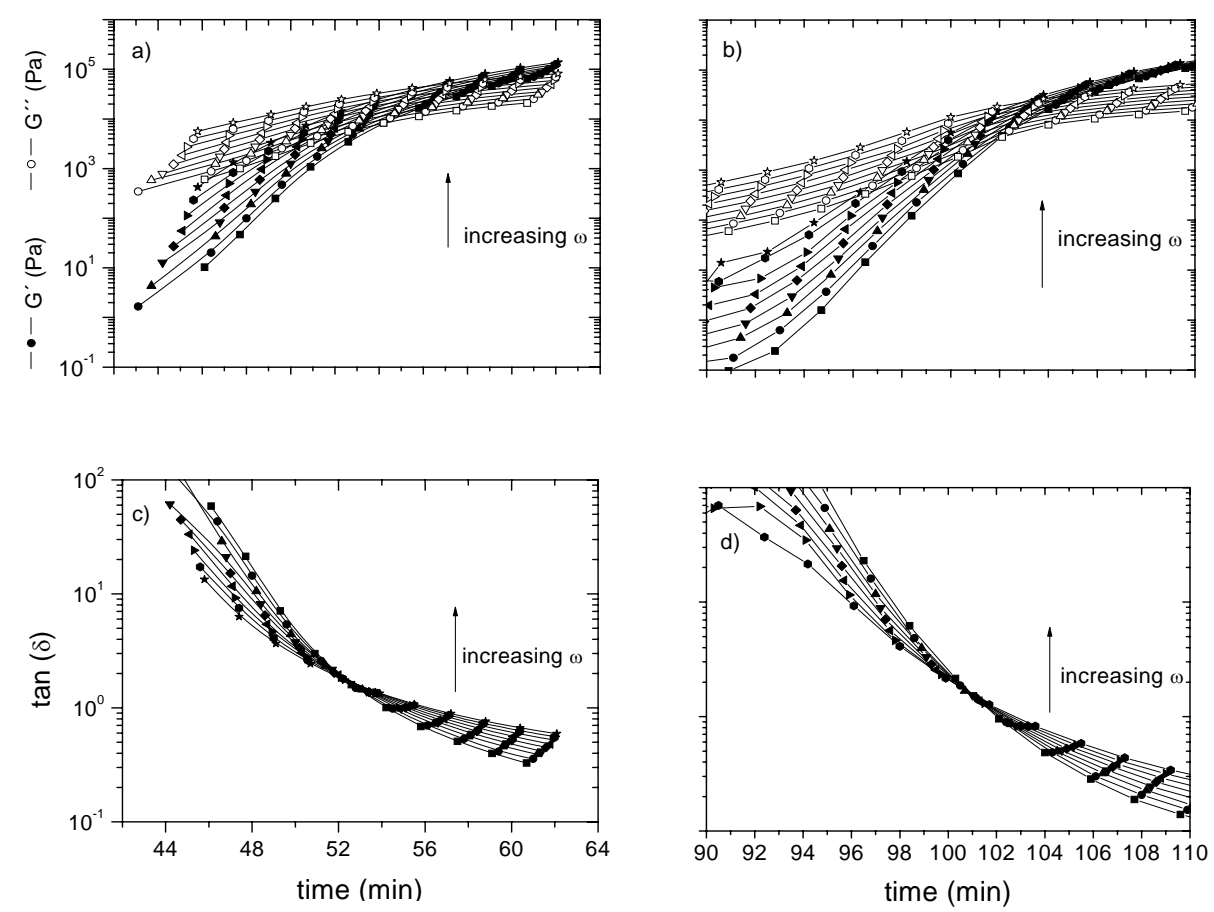

Figure 1. Logarithmic plot of the storage $G^{\prime}(\omega)$, loss, G" $(\omega)$, moduli (parts a and b) and $\tan \delta$ (parts $\mathrm{c}$ and $\mathrm{d}$ ) for isothermal curing as a function of time for different angular frequencies from 5 to $50 \mathrm{rad} \mathrm{s}^{-1}$. The systems studied are epoxy/D230 cured at $75^{\circ} \mathrm{C}$ in parts a) and c), and epoxy/MDEA cured at $130^{\circ} \mathrm{C}$ in parts b) and d). 
Gel time on the epoxy systems was investigated at constant temperature through multi-frequency oscillatory experiments. Figures $1 \mathrm{a}$ and $1 \mathrm{~b}$ show the evolution of the storage modulus, G', and the loss modulus, G", as a function of time for different oscillatory frequencies (5-50 rad/s) for the epoxy pre-polymer cured with Jeffamine D230 at $75^{\circ} \mathrm{C}$ (Figure 1a) and with MDEA at $130{ }^{\circ} \mathrm{C}$ (Figure $1 b$ ). It is observed that the gelation time defined by the time of crossover of G' and G", increases as the oscillatory frequency of the experiment increases. Nevertheless, the gelation time is an intrinsic property of the system and consequently cannot be dependent on the experimental conditions ${ }^{1,2,31}$. In order to determine the gel point another criterion has to be employed. Figures 1c and 1d show the evolution of $\tan \delta$ as a function of time for different oscillatory frequencies $(5-50 \mathrm{rad} / \mathrm{s})$ for the systems epoxy/Jeffamine D-230 at $75^{\circ} \mathrm{C}$ (Figure 1C) and for the system epoxy/MDEA at $130{ }^{\circ} \mathrm{C}$ (Figure 1d). As expected, values of $\tan \delta$ increase as frequency increases before the crossover point, and decrease after it. As can be observed, the value of $\tan \delta$ diminishes with time for all the frequencies studied. However, the decreasing rate of $\tan \delta$ is frequency dependent, being faster for the lower frequencies. At a certain point all the curves intersect, that is, $\tan \delta$ becomes frequency independent. Before the crossover point, $\tan \delta$ decreases as the frequency increases, and after the crossover point $\tan \delta$ increases with frequency. Changes in the material structure have been attained. According to the Winter and Chambon method ${ }^{23}$, the gel time can be defined as the time for $\tan \delta$ to be frequency
Comentario [UdW1]: Both G' and $G^{\prime \prime}$ increase as frequency increases before the gel point, with G" values higher than $G^{\prime}$ ones. After the gel point $G^{\prime}$ values are higher than $G^{\prime \prime}$ values indicating a more rigid structure. ¿Se puede poner algo asi? Yo pondría a solid-like structure en lugar de a more rigid structure

Eliminado: usually

Comentario [UdW2]: ¿Se puede poner algo asi? Puedes escribir algo mas certero. Es correcto y se puede poner la referencia de Nijenhuis (31)....aunque es repetitivo porque luego se describe mejor en el texto 
independent. The application of this method provides gel points of $52.6 \mathrm{~min}$ and $101.1 \mathrm{~min}$ for the epoxy/ D230 and epoxy/MDEA systems, respectively. These values are in good accord with published results ${ }^{32,33}$. That is, reported gel values determined as the time for $\mathrm{G}^{\prime}=\mathrm{G}^{\prime \prime}$ are $57 \mathrm{~min}$ when curing at $80^{\circ} \mathrm{C}$ with polyoxypropylenediamine (Jeffamine D400) ${ }^{32}$ and 115 min when curing at 80 ${ }^{\circ} \mathrm{C}$ with MDEA ${ }^{33}$.

Owing to the structural changes taking place during the gelation process, a study of their evolution was carried out in the vicinity of the gelation point. The rheological behavior of the systems as a function of frequency and the evolution of the critical exponents as a function of time, and its relative distance to the gel
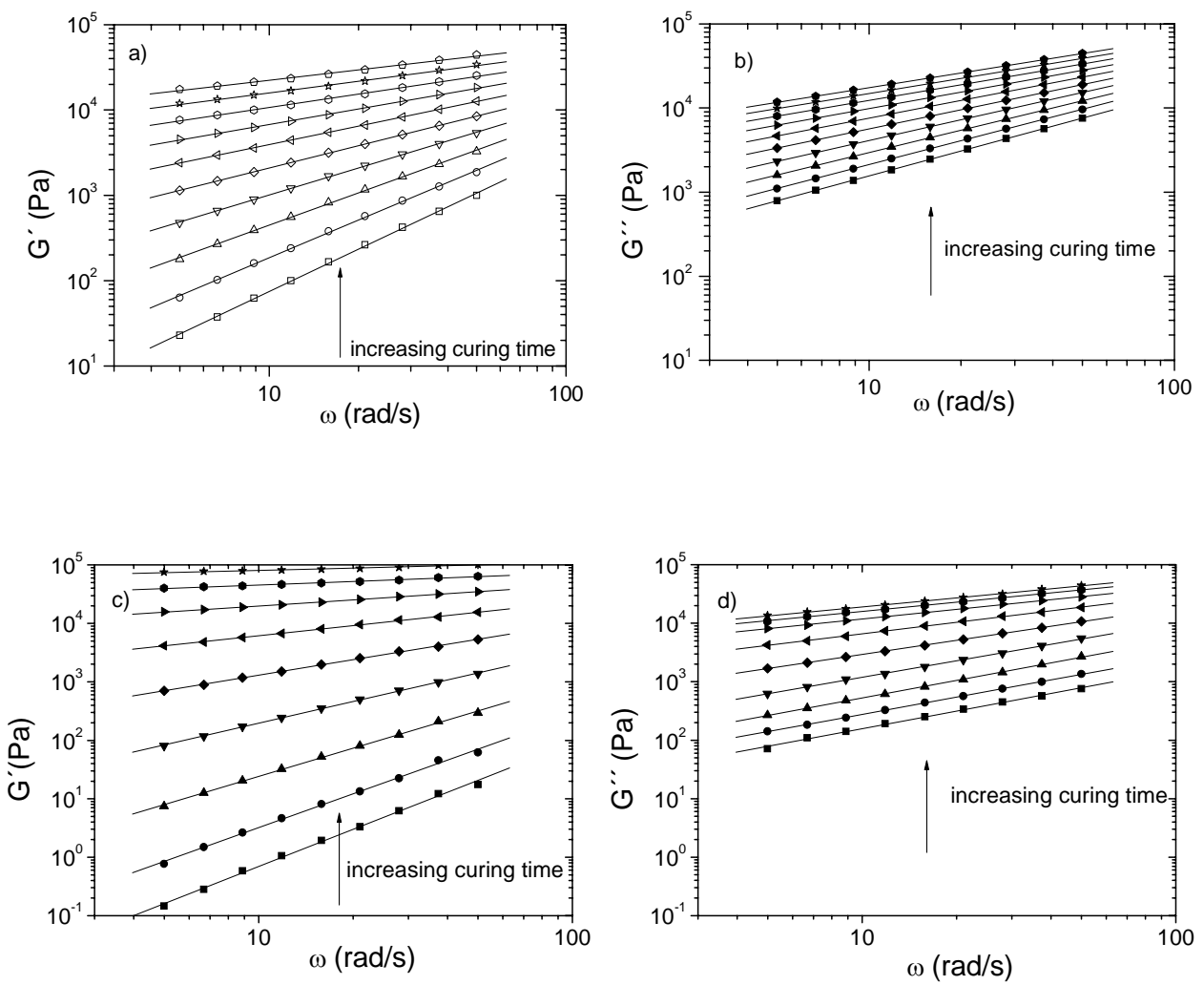
Figure 2. Double logarithmic plot of G' and G" obtained by interpolation of experimental data at different times around the gel point as a function of frequencies. The systems studied are epoxy/D230 cured at $75^{\circ} \mathrm{C}$ in parts a) and b), and epoxy/MDEA cured at $130^{\circ} \mathrm{C}$ in parts c) and d).

point were studied. One of the problems of this kind of study comes from the fact that the points corresponding to each frequency are obtained at increasing times and, therefore, the value of the rheological variables are acquired at different degrees of connectivity as the cross-linking reaction progressed with time. To overcome this problem, it was necessary to interpolate the experimental data to obtain values of G' and G" at the same time, and therefore to study the behavior of the system as a function of frequency. The interpolation was carried out through the fitting of the experimental results to an eighth-order polynomial ${ }^{34}$. Figure 2 depicts the results obtained from the interpolation of the rheological data as the double logarithmic plot of G' and G" as a function of frequency at different reaction times in the vicinity of the gelation point, for the system epoxy/ D230 (Figures 2a and 2b); and for the system epoxy/MDEA (Figures $2 \mathrm{c}$ and $2 \mathrm{~d}$ ). The following observations can be drawn from these figures: i) the double logarithmic plots show a linear dependence of G' and G" with frequency, both G' and G" increase with frequency, ii) the values of G' and G" increase as the reaction time increases, and iii) the slopes of the variation of G' and G" with frequency, defined as n' and n", respectively, decrease with the reaction time and become equal at the gel point. These changes show the switching from a liquid state, characterized by the dependence of the elastic 
modulus with frequency, to a solid state, characterized by the independence of the elastic modulus with frequency. The use of the criterion: $G^{\prime} \propto G^{\prime \prime} \propto \omega^{n}$ at the gel point ${ }^{29}$ gives values of gel times $\left(t_{\text {gel }}\right)$ of $52.3 \min$ and 101.0 min and of $n=$ 0.659 and 0.628 for the systems epoxy/ D230 ${ }^{32}$ and epoxy/MDEA ${ }^{33}$, respectively.

The application of equation 4 allows ${ }^{30}$ the determination of the fractal dimension of the networks formed and provides values of 1.80 and 1.84 for the epoxy/D230 and epoxy/MDEA systems, respectively. These values are in agreement with the occurrence of entropic networks made up of cross-linked flexible chains. Moreover, following equation 5 values of $S_{g}$ are 522 and 360 for epoxy/Jeffamine D230 and epoxy/MDEA, respectively. As $S_{g}$ depends on chain flexibility and cross-linking density ${ }^{23}$, this result suggests stronger gels for the Jeffamine system probably due to more stiffen chains and higher crosslinking densities.

The effect of the type of hardener on the properties of the cured epoxy systems can be resumed as follows: networks obtained with the amine D230 are formed at shorter times, have higher gel strength values and are somewhat more rigid than networks obtained with the amine MDEA.

Rheological behavior of the unmodified S9 sepiolite / epoxy lamine

Comentario [DL4]: Yo no diría que son más rígidos, de hecho no se mide en ningún momento la rigidez de los materiales. Yo hablaría de que presentan un mayor módulo o son más elásticos....como de hecho decís en las conclusiones.

\section{systems during gelation}

The effect of the unmodified sepiolite, S9, on the rheological behavior of the system epoxy/amine during gelation was investigated. In Figure 3, the evolution 
of $\tan \delta$ as a function of time, at different oscillatory frequencies (5-50 rad/s), for the system epoxy/ D230/ sepiolite-S9 at $75^{\circ} \mathrm{C}$ (Figure 3a) and for the system epoxy/MDEA/ sepiolite-S9 at $130^{\circ} \mathrm{C}$ (Figure 3b) are represented. The sepiolite concentrations in both systems were $0.0,2.5,5.0$ and 7.5 phr. The results shown in Figure 3 indicate that the rheological behavior of the epoxy system is affected by the presence of sepiolite. On the one hand, the gel time determined according to the criterion of Winter and Chambon ( $\tan \delta$ independent of frequency) ${ }^{23}$, decreases with sepiolite concentration and, on the other hand, the value of $\tan \delta$ at the gel point does also depend on the clay concentration. The values of the gel point and the critical exponents for the epoxy lamine/ sepiolite S9 systems are collected in Table 1. Gel times determined by the first criteria, $G^{\prime}=G^{\prime \prime}$, are slightly higher than the ones determined by the two other criteria. Either Winter-Chambon or percolation models can be used to determine gelation in unmodified epoxy/ amine/ unmodified sepiolite.

Con formato: Inglés (Estados Unidos)
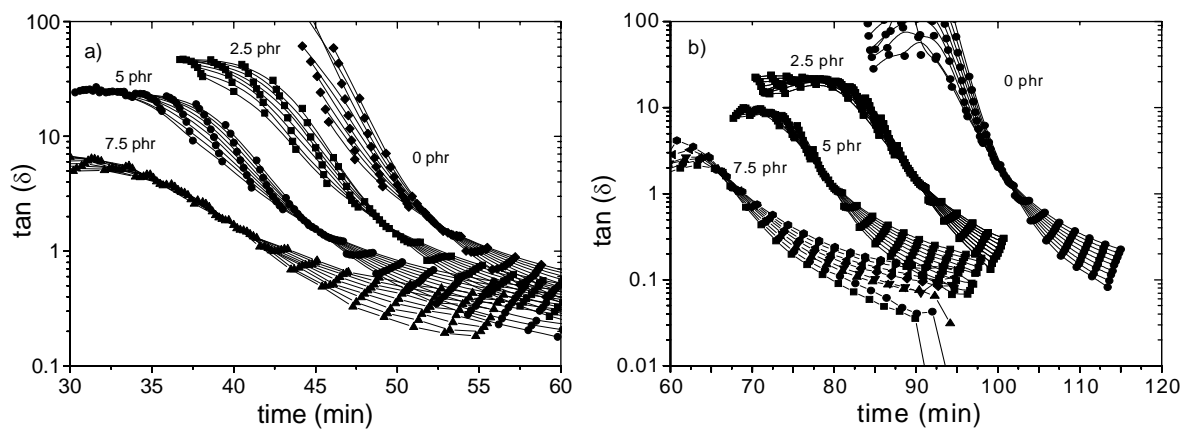

Figure 3. Evolutions of $\tan \delta$ obtained at different frequencies and sepiolite S9 loadings (in phr) for: a) epoxy/D230 cured at $75^{\circ} \mathrm{C}$, and b) epoxy/MDEA cured at $130^{\circ} \mathrm{C}$. 
Whatever the hardener used, the gelation time decreases with the concentration of sepiolite and is more accentuated as the concentration of sepiolite increases. The decrease in gelation time may be due to both: i) an increase in the reaction rate due to a catalytic effect of the sepiolite on the cross-linking reaction, or ii) a decrease in the critical conversion of gelation due to the presence of the particles of sepiolite organized as a physical network ${ }^{17,35-}$ 37.

To study how the structural changes in the physical network of sepiolite particles can affect the gelation process, a study of the evolution of the critical exponents in the vicinity of the gelation point was carried out. As for the pure epoxy/hardener systems presented above, in Figure 4 the double logarithmic plot of G' and G" as a function of frequency is shown for the systems sepiolite S9/ epoxy (concentration 5 phr, as an example) cured with Jeffamine (Figs. 4 a and b), and with MDEA (Figs. $4 \mathrm{c}$ and d). As can be observed, both G' and G" moduli increase with curing time and show a linear dependence with frequency in the double logarithmic plot. This behavior, similar to the pure epoxy/hardener system, indicates an exponential dependence of the moduli with frequency. In Figure 5, the evolution of the critical exponents n' and n" as a function of the relative distance to the gelation point, $\varepsilon$, are represented for the systems epoxy/amine/ S9 sepiolite at different concentrations of the filler (Figures 5 a and $b$ for Jeffamine D-230 and Figure $5 c$ and $d$ for MDEA). $\varepsilon$ is a dimensionless parameter characterizing the region around the gel point defined as: $\varepsilon=\left|\mathrm{t}_{\mathrm{g}}-\mathrm{t}\right| / \mathrm{t}$; where $t$ is any time during the reaction; and $t_{g}$ is the gel point time. Initially, well below the gelation point, the viscoelastic behavior of the systems without 
sepiolite is typical of Newtonian liquids with $n^{\prime}=2$ and $n "=1$. As the reaction proceeds, n' and n" diminish and become equal at the gelation point. After that, the system tends to a hookian behavior with n'=0 and n" $=1 .{ }^{38}$

The addition of sepiolite affects the values of n' and n" that diminish with the concentration of sepiolite for both the Jeffamine and the MDEA systems. This behavior is probably due to interactions between the sepiolite particles and the pre-polymer of the type hydrogen bonding or hydrophobic interactions ${ }^{39}$. These interactions provoke the sepiolite particles to be interconnected through weak links giving rise to a physical network and therefore to an increase of the elastic
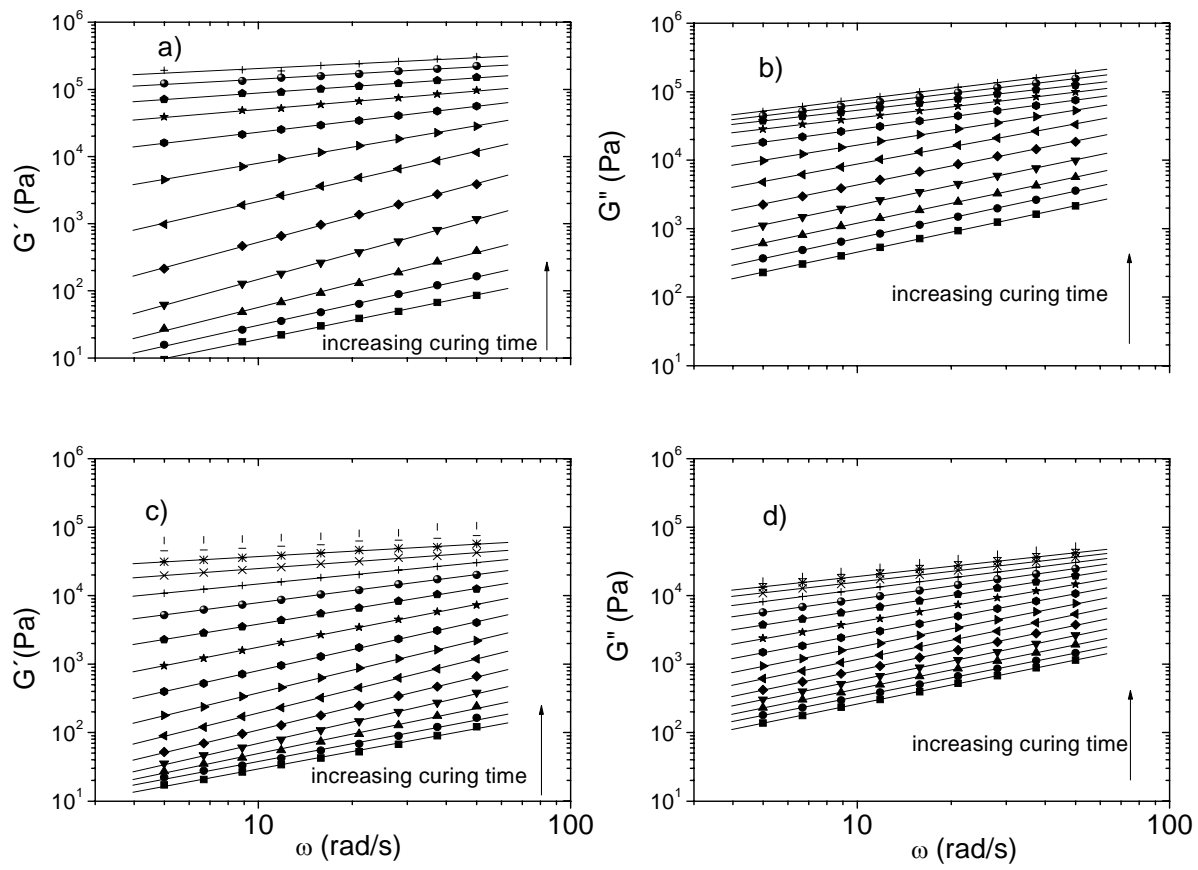

Figure 4. Double logarithmic plot of G' and G" obtained by interpolation of experimental data at different times around the gel point as a function of 
frequencies. The systems studied are epoxy/D230/5phr S9 cured at $75^{\circ} \mathrm{C}$ in parts a) and b), and epoxy/MDEA/ 5 phr S9 cured at $130^{\circ} \mathrm{C}$ in parts c) and d).

modulus and to a quasi solid-like behavior. If we consider the evolution of the critical exponents n' and n" with the reaction time, it can be observed that: well below the gelation time, n' for the epoxy/amine/S9 sepiolite systems increase with the reaction time, unlike for the pure epoxy/amine system. After that, n' reaches a maximum and finally diminish monotonously till becomes equal to n" at the gelation point. The increment of $n$ ' with time indicates a departure from the solid-like behavior to a more viscous behavior. This can be explained considering a breakage of the physical network of the sepiolite particles as the cross-linking reaction of the epoxy system proceeds. A competition between the rupture of the physical network of the filler particles and the chemical network formation of the epoxy/amine system is established that would account for the evolution of the critical exponents with reaction time. 

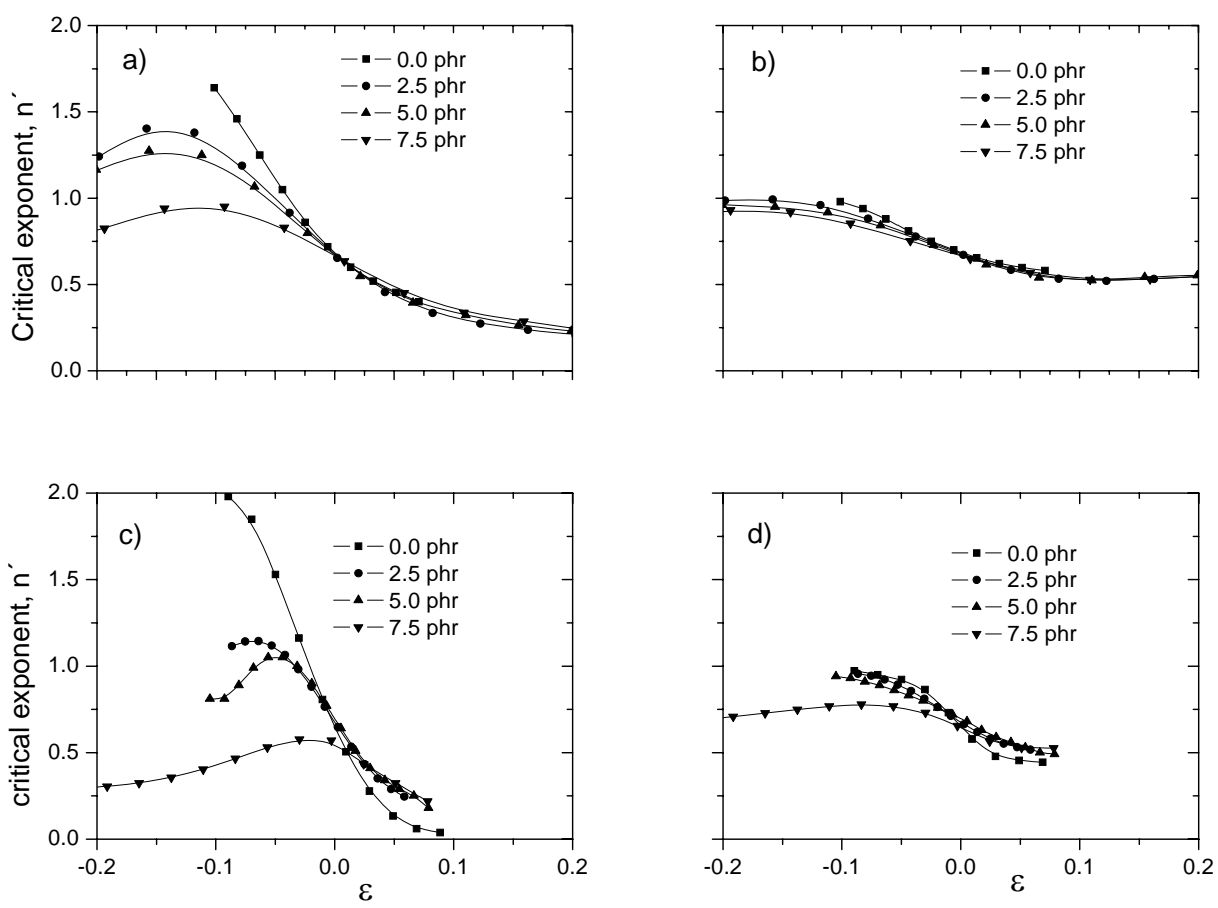

Figure 5. Variation of the power law exponents, n' and n", as a function of $\varepsilon$ for epoxy/D230/ S9 cured at $75^{\circ} \mathrm{C}$ in parts a) and b), and epoxy/MDEA/ S9 cured at $130^{\circ} \mathrm{C}$ in parts $\mathrm{C}$ ) and d).

Both, the increase of $n$ ' with the reaction time and its decrease with the sepiolite concentration indicate that the sepiolite/epoxy/amine system is consistent with a physical network of sepiolite nanoparticles that evolves to a chemical network of the epoxy polymer with dispersed nanofiller as the cross-linking reaction takes place.

The characteristic parameters of the gelation point, that is, the exponent $n$, the corresponding $\tan \delta$, and the gel strength, $S_{g}$, are also dependent on the sepiolite concentration as can be observed in Table $1 . \mathrm{n}$ values are similar to 
the ones determined by the percolation theory, $n=0,7$ and the Rouse model, $n=2 / 3 .{ }^{34,39}$ An important fact is that the evolution of $S_{g}$ and $n$ with sepiolite S9 concentration is different depending on the hardener considered. For the system epoxy/D230/ S9, the relaxation exponent $\mathrm{n}$ diminish, and the gel strength $S_{g}$ increases with filler concentration indicating a more rigid and elastic gel and therefore, a more compact structure. According to the Muthukumar ${ }^{30}$ equation a decrease in the relaxation exponent implies an increase in the fractal dimension of the gel. On the other hand, for the system epoxy/MDEA/S9 the behavior is the opposite: the relaxation exponent $\mathrm{n}$ increases, the fractal dimension decreases, and the gel strength decreases with filler concentration indicating a less rigid, less elastic and more open structure. ${ }^{30,40}$ The cause for the different behavior can be found at the interaction level being the Jeffamine D230 hardener more polar than MDEA and consequently giving rise to stronger interactions with the sepiolite filler. ${ }^{41}$

\section{Rheological behavior of the modified B5 sepiolite / epoxy lamine system during gelation}

A similar study was carried out with an organically surface modified sepiolite (sepiolite B5) with benzyl dimethyl alkyl ammonium. In Figure 6, the evolution of $\tan \delta$ as a function of time, at different oscillatory frequencies (5-50 rad/s) for the system epoxy/ D230/ sepiolite-B5 at $75^{\circ} \mathrm{C}$ (Figure 6a) and for the system /epoxy/MDEA/ sepiolite-B5 at $130^{\circ} \mathrm{C}$ (Figure 6b) are represented. The sepiolite 
concentrations in both systems were $0.0,2.5,5.0$ and 7.5 phr. The observation of these Figures allows us to extract important differences in relation to the systems with unmodified sepiolite: i) the value of $\tan \delta$ diminish with frequency for both hardeners at any filler concentration; ii) the values of $\tan \delta$ increase with reaction time, goes through a maximum and then diminish; iii) the decrease of $\tan \delta$ is frequency dependent, being faster for the low frequencies, nevertheless contrary to the systems with unmodified sepiolite, the curves corresponding to different frequencies do not intersect, that is, $\tan \delta$ do not become frequency independent, except for the sample epoxy/D230/ B5(2.5phr). The last effect becomes more evident as the concentration of sepiolite B5 increases. Experiments of $G^{\prime}$ and $G$ " of epoxy-sepiolite dispersions as a function of frequency show a higher G' than G" value at concentrations higher than 5 phr in presence of organically modified sepiolite. Moreover, FTIR determinations (not shown here) indicate no chemical cross-linking prior to the rheological experiments. All these statements point to the formation of a physical network of sepiolite particles previous to the curing process, being the transition from a physical to a chemical network more apparent than for the unmodified sepiolite system. ${ }^{39}$ 

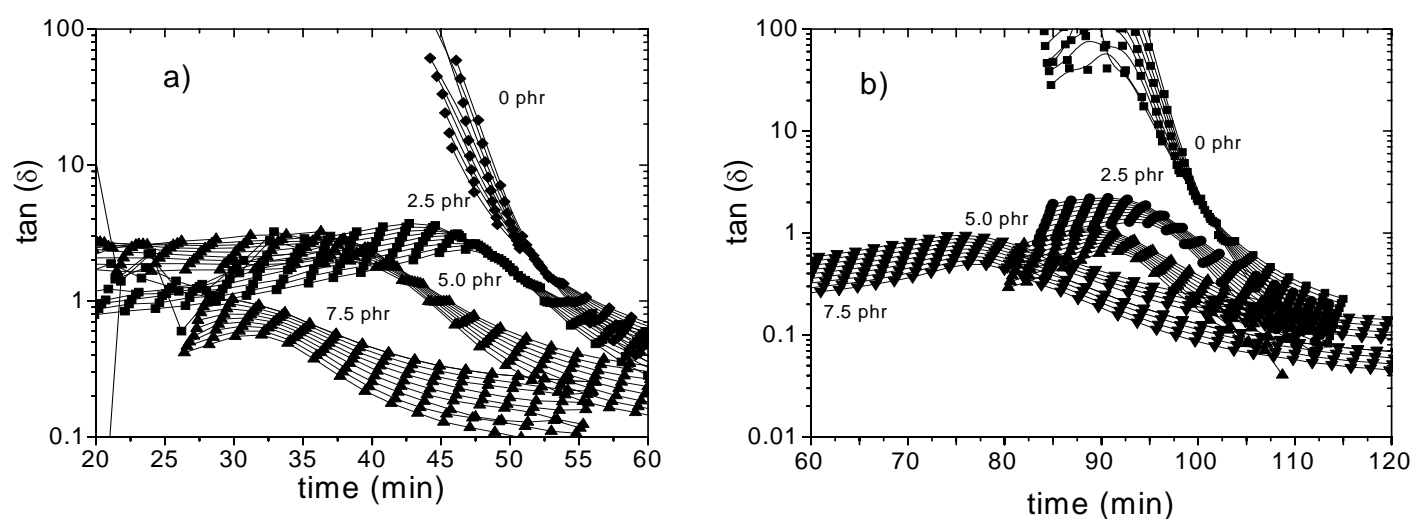

Figure 6. Evolutions of $\tan \delta$ obtained at different frequencies and sepiolite B5 loadings (in phr) for: a) epoxy/D230 cured at $75{ }^{\circ} \mathrm{C}$, and b) epoxy/MDEA cured at $130^{\circ} \mathrm{C}$.

In Figure 7, the evolution of the critical exponents n' and n" as a function of the relative distance to the gelation point are represented for the systems epoxy/amine/ sepiolite B5 at different concentrations of the filler (Figures 7a and 7b for Jeffamine D-230 and Figure 7c and 7d for MDEA). As can be observed, the decrease of the critical exponents $n^{\prime}$ and $n^{\prime \prime}$ in relation to the pure epoxy/amine systems is more dramatic with the modified B5 than with the unmodified S9 sepiolite. Owing to the surface modification of the sepiolite, the interactions between the pre-polymer and the sepiolite are stronger giving rise to physical gels with a solid like behavior ( $\left.G^{\prime}>G^{\prime \prime}\right)$ and consequently, with lower values of n' and n". As for the system with the unmodified sepiolite, the difference between n' and n" diminish as the cross-linking reaction proceeds. 

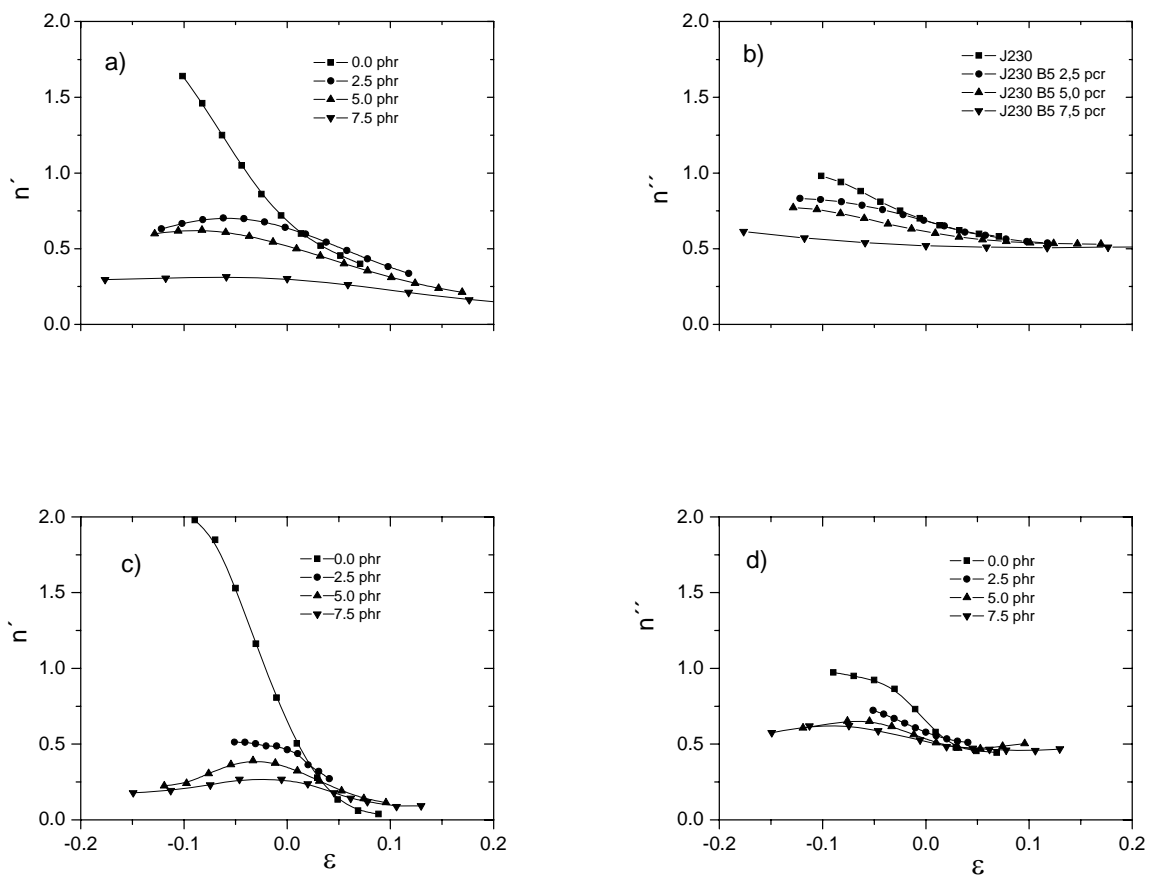

Figure 7. Variation of the power law exponents, n' and n", as a function of $\varepsilon$ for epoxy/D230/ B5 cured at $75^{\circ} \mathrm{C}$ in parts a) and b), and epoxy/MDEA/ B5 cured at $130^{\circ} \mathrm{C}$ in parts $\mathrm{C}$ ) and d).

Nevertheless at a certain reaction time, the difference between n' and n" begins to increase and the critical exponents do not crossover. The criterion of Winter and Chambon is not fulfilled and the gelation point cannot be determined. To study the effect of the filler concentration on the gelation time a new criterion has to be established: the gelation time is considered as the time for which the difference between n' and n" reaches a minimum. The values of the gelation times are shown in Table 2. 
The data in Table 2 show that the addition of sepiolite B5 provokes a decrease in the gelation times of the same order of magnitude as the addition of unmodified sepiolite. As the Winter and Chambon criterion is not fullfiled, it is not possible to calculate the value of the gel strength for the cured systems. Neverthless, the lower values of the critical exponents obtained for the systems with the modified sepiolite indicate that the gels formed with this clay are more rigid.

\section{Conclusions}

This study shows the utility of rheological studies in understanding the effect of nanoparticles on the gelation process in thermoset polymer nanocomposites. The unfilled and the non-modified sepiolite epoxy systems obey the WinterChambon criterion at the gel point since the loss tangents intersect at a single point in multifrequency rheological measurements. However, for the organically modified sepiolite a physical gel is formed and G' is higher than G" for concentrations higher than 5 phr when curing with MDEA and higher than 7.5 phr in presence of D230. The three parameters $\tan \delta, n$ and $S_{g}$ at the gel point evaluate the gel properties. A more elastic gel with higher gel strength is obtained in presence of the non-modified sepiolite as curing proceed in presence of the aliphatic diamine, D230.

\section{References}

1 Pascault JP, Sautereau H, Verdu J and Williams RJJ, Thermoseting Polymers. Marcel Dekker, New York (2002). 
2 "Epoxy polymers: new materials and Technology" JP Pascault, RJJ Williams Eds, Wiley-WCH, Weinheim, 2010.

3 Pinnavaia TJ and Beall GW, Polymer-Clay Nanocomposites. John Wiley, Chichester (2001).

4 (a) Darder M, López-Blanco M, Aranda P, Aznar AJ, Bravo J and RuizHitzky E, Chem Mater 18 (6): 1602-1610 (2006). (b) Kavas T, Sabah E and Çelik MS, Cem Concr Res 34 (11): 2135-2139 (2004).

5 (a) Preisinger A, Clays Clay Miner. 6: 61-67 (1959). (b) Santarén J, Sanz J, Ruiz-Hitzky E, Clay Miner. 38: 63-68 (1990).

6 Torro-Palau A, Fernández García JC, Orgiles-Barcelo C, Pastor Blas M and Martin-Martínez JM, J Adhes Adhesives 17: 111 (1997).

7 Ruíz R, del Moral JC, Pesquera C, Benito T and González F, Thermochim Acta 279: 103 (1996).

8 Bokobza L, J Appl Polym Sci 93(5): 2095-2104 (2004).

9 Bokobza L, Burr A, Garnaud G, Perrin MY and Pagnotta S, Polym Int 53(8): 1060-1065.

10 Bokobza L, Leroy E and Lalanne V Eur Polym J 45: 996-1001 (2009).

11 Roy N and Bhowmick AK, Polymer 51: 5172-5185 (2010).

12 Bilotti E, Zhang R, Deng H, Quero F, Fisher HR and Peijs T, Compos Sci Technol 69: 2587-2595 (2009). 
13 Rong J, Jing Z, Hong $X$ and Zhang W, "Polyolefin-clay nanocomposites and process for the preparation thereof. U.S. Patent 6444742, 2002.

14 García-López D, Fernández JF, Merino JC, Santarén J and Pastor JM, Comp Sci Tech 70: 1429-1436 (2010).

15 Xie S, Zhang S, Wang F, Yang M, Séguéla R, Lefebvre JM, Comp Sci Tech 67: 2334-2341 (2007).

16 Nohales A, Muñoz-Espi R, Félix P and Gómez CM, J Appl Polym Sci 119: 539-547 (2011).

17 Franchini E, Galy J and Gérard JF, J Colloid Interface Sci 329: 38-47 (2009).

18 Sangerano M, Pallaro E, Roppolo I and Rizza G, J Mater Sci 44: 31653171 (2009)

19 Zheng Y and Y Zheng Y, J Appl Polym Sci 99: 2163-2166 (2006).

20 Winter HH, Polym Eng Sci 27: 1698-1702 (1987).

21 Hu X, Fan J and Yue CY, J Appl Polym Sci 80: 2437-2446 (2001).

22 Tung C-Y M and Dynes PJ, J Appl Polym Sci 27: 569-574 (1982).

23 Winter HH and Chambon F, J Rheol 30: 367-382 (1986).

24 Chiou BS, Raghavan SR and Khan SA, Macromolecules 34: 4526-4533 (2001).

25 Helmy AK and de Bussetti SG, Appl Surf Sci 255: 2920-2924 (2008). 
26 Tung CYM and Dynes PJ, J Appl Polym Sci 27: 569-574 (1982).

27 Chambon F, Petrovic ZS, Macknight WJ and Winter $\mathrm{HH}$, Macromolecules 19: 2146-2149 (1986).

28 Chambon F and Winter HH, J Rheol 31: 683-697 (1987).

29 Martin JE, Adolf D and Wilcoxon JP, Phys Rev Lett 61: 2620-2623 (1988).

30 Muthukumar M, Macromolecules 22: 4656-4658 (1989).

31 te Nijenhuis K, Advances in Polymer Science 130: 1-267 (1997).

32 Huang ML, Williams JG, Macromolecules 27: 7423-7428 (1994).

33 Girard-Reydet E, Riccardi CC, Sautereau H, Pascault JP, Macromolecules 28: 7599-7607 (1995).

34 Lairez D, Adam M, Emery JR and Durand D, Macromolecules 25: 286289 (1992).

35 Becker O, Simon GP, Varley RJ and Halley PJ, Polym Eng Sci 43: 850 (2003).

36 Pethrick RA, Miller C and Rhoney I, Polym Int 59: 236-241 (2010).

37 Asif AA, John B, Rao VL and Ninan KN, Polym Int 59: 986-997 (2010).

38 Lange J, Johansson M, Kelly CT and Halley PJ, Polymer 40: 5699-5707 (1999).

39 Meng J, Hu X, Boey FYC and Li L, Polymer 46: 2766-2776 (2005). 
40 Scanlan JC and Winter HH, Macromolecules 24: $47-54$ (1991).

41 Kornmann X, Lindberg $\mathrm{H}$ and Berglund LA, Polymer 42: 4493-4499 (2001). 
Table 1. Gel times at different criteria, critical exponent, $n, \tan \delta$, fractal dimension, $d_{f}$, and gel strength, $S_{g}$ for epoxy-sepiolite $S 9$ cured with D230 at 75 ${ }^{\circ} \mathrm{C}$ and with MDEA at $130^{\circ} \mathrm{C}$.

\begin{tabular}{|c|c|c|c|c|c|c|c|c|}
\hline Hardener & \multicolumn{4}{|c|}{ D-230 } & \multicolumn{4}{|c|}{ MDEA } \\
\hline$\overline{p h r}$ & 0.0 & 2.5 & 5.0 & 7.5 & 0.0 & 2.5 & 5.0 & 7.5 \\
\hline $\begin{array}{c}t_{\text {gel }}(\min ) \\
\left(G^{\prime}=G^{\prime \prime}, 5 \mathrm{rad} / \mathrm{s}\right)\end{array}$ & 54.2 & 51.1 & 46.7 & 42.0 & 102.0 & 91.0 & 80.3 & 75.2 \\
\hline $\begin{array}{l}t_{\text {gel }}(\min ) \\
\tan \delta \neq f(\omega)\end{array}$ & 52.6 & 49.7 & 45.1 & 40.4 & 101.1 & 89.8 & 79.2 & 74.2 \\
\hline $\begin{array}{c}\mathrm{t}_{\mathrm{gel}}(\min ) \\
\mathrm{n}^{\prime}=\mathrm{n}^{\prime \prime}\end{array}$ & 52.3 & 49.8 & 45.0 & 39.7 & 101.0 & 89.8 & 79.3 & 74.2 \\
\hline$n$ & 0.659 & 0.637 & 0.636 & 0.628 & 0.628 & 0.639 & 0.645 & 0.648 \\
\hline $\tan \delta$ & 1.685 & 1.559 & 1.554 & 1.512 & 1.512 & 1.570 & 1.603 & 1.620 \\
\hline$d_{f}$ & 1.80 & 1.83 & 1.83 & 1.84 & 1.84 & 1.82 & 1.81 & 1.81 \\
\hline$S_{g}$ & 522 & 1115 & 1556 & 1358 & 360 & 267 & 43.7 & 32.4 \\
\hline
\end{tabular}


Table 2. Gel times for epoxy-sepiolite B5 cured with D230 at $75^{\circ} \mathrm{C}$ and with MDEA at $130^{\circ} \mathrm{C}$.

\begin{tabular}{|c|c|c|c|c|c|c|c|c|}
\hline Hardener & \multicolumn{4}{|c|}{ D-230 } & \multicolumn{4}{|c|}{ MDEA } \\
\hline phr & 0.0 & 2.5 & 5.0 & 7.5 & 0.0 & 2.5 & 5.0 & 7.5 \\
\hline $\begin{array}{c}t_{\text {gel }}(\min ) \\
\left(G^{\prime}=G^{\prime \prime}, 5 \mathrm{rad} / \mathrm{s}\right)\end{array}$ & 54.2 & 52.4 & 44.1 & $G^{\prime}>G^{\prime \prime}$ & 102.0 & 97.0 & $G^{\prime}>G^{\prime \prime}$ & $G^{\prime}>G^{\prime \prime}$ \\
\hline $\begin{array}{c}\mathrm{t}_{\mathrm{gel}}(\min ) \\
\left(\mathrm{n}^{\prime}-\mathrm{n}^{\prime \prime}\right)_{\text {minimun }}\end{array}$ & 52.3 & 49.7 & 42.22 & 33.3 & 101.1 & 98.0 & 96.1 & 82.3 \\
\hline
\end{tabular}

